https://doi.org/10.31713/m905

\title{
RECLAMATION OF DESTRUCTED LANDS OWING TO ILLEGAL AMBER PRODUCTION IN NORTHERN RE- GIONS OF UKRAINE
}

\author{
Korniyenko V.Ya. \\ National University of Water and Environmental Engineering \\ (NUWEE), Doctor of Engineering, Professor, Department of Mining \\ and Mining, Ukraine
}

Chukharev S.M.

National University of Water and Environmental Engineering (NUWEE), Ph.D., Associate Professor, Department of Mining and Mining, Ukraine

\section{Zaiets V.V.}

National University of Water and Environmental Engineering (NUWEE), Ph.D., Associate Professor, Department of Mining and Mining, Ukraine

\section{Vasylchuk O.Yu.}

National University of Water and Environmental Engineering (NUWEE), Ph.D., Associate Professor, Department of Mining and Mining, Ukraine

\begin{abstract}
This section analyses the state of disturbed lands as a result of the illegal extraction of amber in the Rivne region. The general characteristics of the territories and the negative consequences of illegal amber production are given. Were analysed and found possible future composition of vegetation of specific Dubrovytsky forestry area. The main stages and directions of reclamation of disturbed lands are considered. As a result of the analysis of literary sources and archival data, possible options for reclamation on the disturbed lands were suggested. It has been established that conducting a complete reclamation of sites damaged by illegal amber production is the only technically available method, given the nature and extent of the violation of these lands. It has also been found that the pilot-industrial extraction with $100 \%$ the extraction of the remaining amber is a prerequisite for preventing the repeated illegal intervention of the diggers on the reclaimed land. It is established that after the completion of the pilot-industrial extraction and technical reclamation it is necessary to
\end{abstract}


conduct additional ecological and economic assessment of the disturbed territories in order to further extract amber, forestry and use for agricultural production

\section{Introduction}

The problem of illegal extraction of amber in the forest lands of the Ukrainian Polissia (Volyn, Rivne and Zhytomyr regions) has existed for more than 15 years, but it has become a particularly urgent subject of public attention in recent years, primarily due to the efforts of the public and the media.

The illegal activities of the "diggers" cause serious economic losses to the state and society, accompanied by deterioration of the social climate, leads to the degradation of large areas of forest lands, the deterioration of the ecological situation. Since disturbed biotopes cannot be restored naturally, without human intervention, they require reclamation [1-3].

The state, represented by central and local authorities, both legislative and executive, is forced to make efforts to resolve the problem, but no significant changes have been made.

One of the areas of intervention by the state authorities and the public is the activity of practical implementation of reclamation of the affected areas. To this end, the Cabinet of Ministers approved a resolution of the Cabinet of Ministers of November 30, 2016 No. 1063, which approved the "Procedure for the implementation of a pilot project of reclamation of forestry lands damaged as a result of illegal amber production". According to this resolution, the Order of the State Forestry Agency of Ukraine No. 138 of 21.04.2017 established the "List of forest lands, within which there are parts that are damaged due to illegal amber production and need reclamation", which included 2046 disturbed areas with a total area of 30037.6 ha. Therefore, the issue of reclamation of disturbed lands due to illegal amber mining is undeniably topical.

The subject of the study is the assessment of the ecological status of forest lands disturbed by illegal amber production that require reclamation.

The object of research is the forest areas of Rivne region, which have been affected by illegal amber production. 
The purpose of the research is to assess the overall ecological status of the disturbed lands and to establish acceptable areas for their reclamation.

These studies were conducted by studying, analysing and generalizing literary including archival data.

\section{General characteristics of disturbed lands}

The territory on which the disturbed forests are located is in the western part of the mixed forest zone, which is called the Ukrainian Polissia, of the Eastern European Plain within the Volyn Polissia region (Fig. 1).

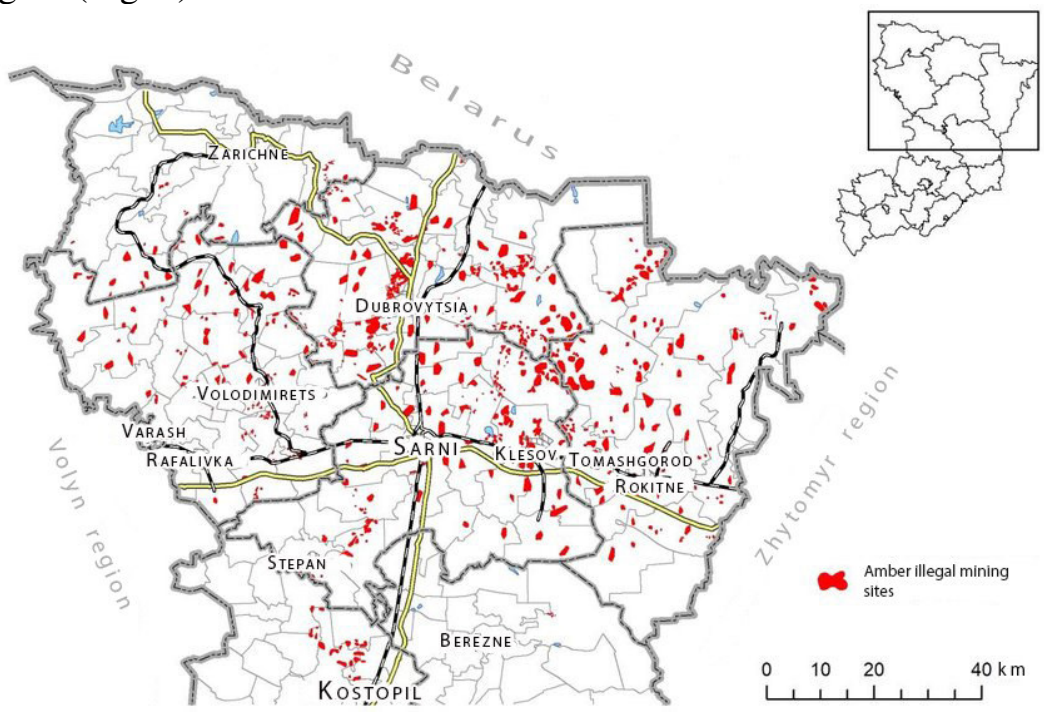

Fig. 1. Positioning of sites of illegal amber production in the territory of Rivne region

Ukrainian Polissia is a kind of physical-geographical province of the mixed forest zone of the Eastern European Plain. The surface is characterized by a slight degree of land dismemberment, a general slope to the north, considerable afforestation (pine and mixed deciduous forests), wetlands, the presence of a dense network of watercourses, with a clear division into watersheds and river valleys.

The climate is temperate continental with warm summers, mild winters and heavy rainfall. The maximum precipitation falls in JuneJuly, the minimum in January-February. In rainy years, rainfall 
reaches $900 \mathrm{~mm}$. The total number of days with precipitation is 160190 . The average annual relative humidity is $80 \%$, the average annual temperature is $6.6-7^{\circ}$, the maximum average monthly temperature of air is $17-19^{\circ}$ fixed in July, the minimum $\left(-6^{\circ}\right)$ - in January.

The territory is dominated by sod-podzolic, sandy and marsh soils. Wetlands occupy large areas, which is facilitated by physical and geographical conditions, the nature of the relief and the hydrodynamic features of the area.

In geostructural terms, the territory is located within the northwestern outskirts of the Ukrainian Crystalline Massif and is characterized by the presence of two structural floors: the lower one, which is represented by crystalline rocks of the foundation, and the upper one, which consists of horizontally lying sedimentary formations. The crystalline basement complex formed by ancient metamorphic and magmatic rocks are in their age of Archean and Proterozoic.

Soil cover of disturbed lands is diverse in genesis, mechanical composition, water-physical properties and fertility.

The relative plainness of the territory of the region and the low flow of groundwater led to the formation of large areas of wetland soils In the few elevated areas formed sod-podzolic soils, and the more elevated dominated loose sands. Swamp soils cover $50 \%$ of the area here, sod-podzolic - $29 \%$, sod - $6 \%$, meadow - 5\%, sand hills about $10 \%$.

The investigated area covered with wood (birch, hornbeam, alder, pine) with a typical shrub and moss vegetation (Table. 1).

To visualize the dynamics of change of forest cover, the archive data of the change of terrestrial cover of the quarter № 59 of Dubrovitske Forestry are presented below (Table 2, Fig. 2). Also are provided forecast data, in the absence of legislative regulation of the issue of illegal amber production.

Table 1

Specific composition of the forest fund in the context of forestry in the region

\begin{tabular}{l|c|c|c|c|c|c}
\hline \multicolumn{1}{c|}{ Forestry } & Pine, Ha & Oak, Ha & Birch, Ha & Alder, ha & $\begin{array}{c}\text { Spruce,. } \\
\text { Ha }\end{array}$ & $\begin{array}{c}\text { Hornbeam, } \\
\text { Ha }\end{array}$ \\
\hline Bereznivske & 34082,2 & 2379,7 & 6263 & 4569 & 85 & 226 \\
\hline Volodimiretske & 46947,5 & 2479,7 & 11822,9 & 12724,4 & 382 & 203 \\
\hline Dubrovitske & 27516,8 & 2205,1 & 8839,4 & 3746,1 & 147.2 & 134 \\
\hline Zarichnenske & 20210,7 & 1349,4 & 5023,6 & 5752,4 & 235,4 & 97 \\
\hline
\end{tabular}




\begin{tabular}{l|c|c|c|c|c|c}
\hline Klesivske & 34069,5 & 1191,2 & 7263,7 & 2607,7 & 125,2 & 14,8 \\
\hline Kostopilske & 19328,8 & 3116,3 & 4266,6 & 4754,9 & 307,8 & 104,8 \\
\hline Rokitnovske & 35760,4 & 736,8 & 6382,7 & 2138 & 93,7 & 57,3 \\
\hline Sarnenske & 27461,5 & 1246 & 6030,1 & 4017,3 & 144.7 & 64,7 \\
\hline
\end{tabular}

Table 2

Dynamics of change of forest cover of quarter №59 of Dubrovitske forestry as a $\%$ of the total area

\begin{tabular}{l|c|c|c|c}
\hline Type of territory / year & 2009 & 2015 & 2017 & 2021 \\
\hline Amber extraction area & 0,1 & 2,6 & 2,3 & 3,5 \\
\hline $\begin{array}{l}\text { The surface is small and / or not covered } \\
\text { with vegetation }\end{array}$ & 3,1 & 13 & 12,9 & 14 \\
\hline Surface covered with undersized vegetation & 0,3 & 2 & 2 & 4,5 \\
\hline Deciduous forest & 65,5 & 61,1 & 58,6 & 58,2 \\
\hline Coniferous forest & 31 & 21,2 & 24,1 & 19,7 \\
\hline
\end{tabular}

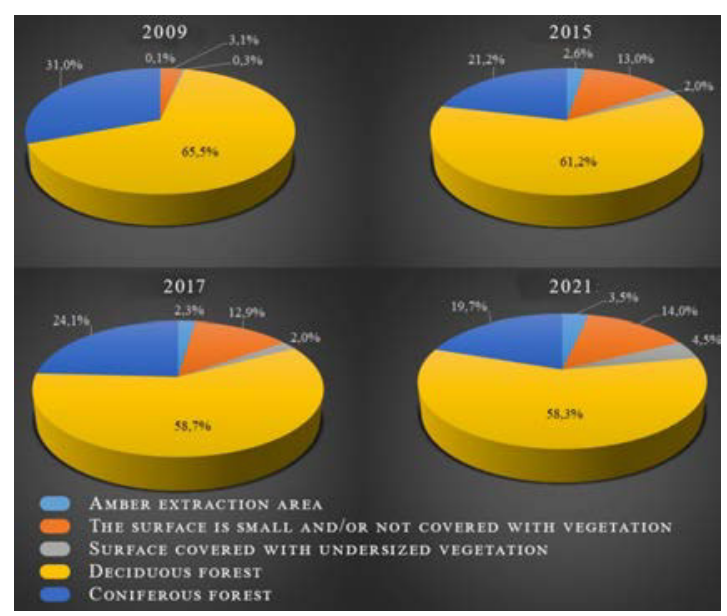

Fig. 2. Dynamics of change of forest cover of quarter №59 of Dubrovitsky forestry

\section{The negative environmental effects of illegal amber produc- tion}

It is clear that the illegal extraction of amber by common methods (trenching, underground hydraulic leaching, erosion in pits) has a negative impact on the ecological state of territories development.

An illegal production is uncontrolled, and not only in terms of raw materials extraction, but also in terms of extraction - violation of natural territories. Nature is a complex system where all the components 
are inextricably linked with one another. Therefore, disturbance of the geological environment inevitably causes negative changes in adjacent environments. The most negative impact is in the biotic component of nature [4-6].

When amber extraction method is trenching it completely destroys grass and shrub layer of the forest mechanically and damages root system of trees, and frequent trees often are cut and uprooted. Due to lack of soil and due to damage, the root system is not able to hold the trunk upright and the trees tilt or fall at all under their own weight (Fig. 3).

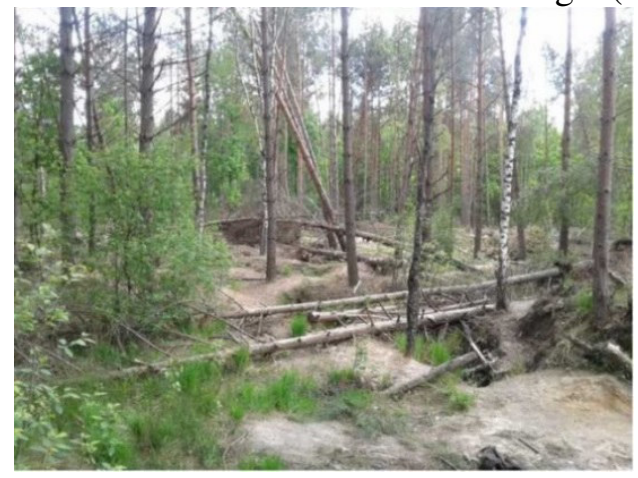

Fig. 3. Vegetation in the Rivne region after illegal extraction of amber

In this case, nearby plants may be damaged, the undergrowth dies. Over time, most trees die. Such territories are characterized by the almost complete absence of primary soil cover, but the huge number of pit holes reduces the area for seed development and, consequently, for the development of young forest.

This destroys the modern forest and does not create the conditions for its restoration.

A similar, but at the same time, another situation is observed in the extraction of amber by the hydropump method (Fig. 4). There are two types of negative consequences.

The first is the creation of funnel-like cavities in the soil, its overlapping with the covered material; other - breach hydrogeological regime of the area from the inflow of large amounts of water.

Mechanical impact on soil is its subsidence and burial under a layer of sandy-clay material. Excessive additional wetting with process water leads to a long rise in the groundwater level [7-9]. 




Fig. 4. "Moon relief" after the hydropump illegal extraction method of amber

As a result, the root system of the trees is incapable of keeping them in equilibrium in sparse sandy soil. Also raised groundwater level prevents the penetration of oxygen to the roots and they die from waterlogging. When the number of dead roots reaches the critical limit, the plant dies completely. The difference with the hydropumping method is that the soil and rock do not move into the dumps, but are evenly distributed throughout the territory by water flows, creating conditions for further self-healing of the forest.

On the basis of the analysis of the condition of the affected areas, it was found that the species similarity of the floristic composition of the majority of forest groups after amber extraction in the studied areas is very low.

It should be noted that deep canals were dug for pumping amber by pumps, which drain forests over large areas, which leads to changes in the hydrological regime of the area and weakens the ecological stability of forest ecosystems [10-12].

It was also found that in most cases the number of species in disturbed areas was lower than the original phytocenoses. This is indicative of the total destruction of phyto-diversity due to the illegal extraction of amber.

\section{Known stages and directions of reclamation}

Land reclamation is the implementation of various works that aim not only at the partial transformation of natural territorial complexes disturbed by industry, but also at creating in their place even more productive and rationally organized elements of cultural anthropogen- 
ic landscapes. That is, it involves the optimization of man-made landscapes, the improvement of environmental conditions.

The following terms are distinguished in a concise dictionary on land reclamation (1980): temporary land reclamation, permanent land reclamation and reclamation of landscapes.

Temporary reclamation is carried out on lands where their use is planned to change in the future. This reclamation is usually reduced to planting and fixing surface erosion, and compliance with hygiene standards.

Permanent reclamation is carried out on the land where the change does not provide the previous use of the land.

Reclamation of landscapes is a land reclamation, which is not limited to local measures to "tidy up" individual disturbed areas, but involves the complex transformation of disturbed land in the general system of measures to optimize man-made landscapes.

At the present stage of society development, many domestic and foreign scientists consider the reclamation of disturbed lands as a complex problem of restoring the productivity and reconstruction of landscapes disturbed by industry, created on the site of "industrial deserts" of new cultural landscapes.

The state standard "Nature Conservation. Land reclamation. Terms and definitions" treats reclamation as a complex of works aimed at restoring the productivity and national economic value of land, as well as improving the environmental conditions.

All the processes of reclamation of disturbed land are divided into two main stages: mining technical and biological. However, in practical terms considered more appropriate definition of three phases: preparatory, mining technical and biological.

The preparatory or design phase includes the examination and typing of disturbed and infringed lands; study the properties of cover soils and classify them as suitable for biological reclamation; determination of directions and methods of reclamation; drawing up feasibility studies (FS) and technical work on reclamation projects.

Mining technical, or engineering, a step, also called technical or mining technical reclamation, involves the completion of work on the preparation of lands released after mining operations for further targeted use in the economy. The following works are performed at this stage: 
- selective removal, storage and preservation of cover soils suitable for biological reclamation, including fertile soil;

- selective formation of cover soils dumps;

- if necessary planning and coverage of the planned surface layer of fertile soil or potentially fertile soil;

- backfilling and planning of deformed surfaces (dips, karst funnels, etc.);

- installation of access roads;

- ameliorative and anti-erosion measures.

In the reclamation of disturbed forest lands, the technical stage includes only works related to the conservation and reuse of fertile soil (if available), surface planning, and (if necessary) chemical reclamation and ordering of drainage networks.

Biological reclamation is a set of measures to create favourable water-air and nutrient regimes for crops and forestry. The complex of measures of biological land reclamation is determined by the physicochemical properties of the underlying rocks and the applied fertile soil layer or potentially fertile rock. This complex covers the introduction of crop rotations, saturated with crops for fertilizer, the introduction of high standards of organic and mineral fertilizers, mulching etc.

The areas of reclamation determine the end use of the disturbed lands after the relevant mining, engineering, hydrotechnical and other measures. they are selected on the basis of a comprehensive account of the following factors:

- natural conditions of the deposit area (climate, soil types, geological structure, vegetation, wildlife, etc.);

- condition of disturbed lands up to the moment of reclamation (nature of technogenic relief, degree of natural overgrowth, etc.);

- mineralogical composition, water-physical and physicalchemical properties of rocks;

- agrochemical properties (nutrient content, acidity, presence of toxic substances, etc.) of rocks and their classification by suitability for biological reclamation;

- geotechnical and hydrological conditions;

- economic, socio-economic, environmental and sanitary conditions; 
- service life of reclamation lands (possibility of repeated violations and their periodicity);

- technology and mechanization of mining and construction works.

The most common are the following areas of land reclamation:

- agricultural;

- forestry;

- water management;

- recreational;

- sanitary and hygienic;

- constructional.

\section{Possible reclamation on disturbed lands}

Reclamation works consist in the implementation of a set of organizational, technical and biotechnological measures aimed at restoring soil cover, improving the condition and productivity of disturbed forest lands, creating new plantations (biological reclamation).

Reclamation of disturbed forestry land has a direct impact on the following environmental components:

- soil cover;

- vegetation cover;

- soil (first from the surface) aquifer, including conditions of infiltration of precipitation and snowmelt;

- terrain, including surface planar runoff and snowmelt conditions.

Given that the existing parameters of all the above components of the environment are significantly impaired, they are under the influence of long-term degradation, or even close to those that have completely lost their natural potential (topsoil, groundwater, tree stand), and their reclamation restoration, it is safe to say that in general the planned list of works does not cause any negative environmental impacts.

Preparatory work should include the removal of the remains of disturbed stands, other perennial vegetation affected by illegal amber mining activities, tree stumps, etc.

Probably some of the wood (branches, shrubs, debris, etc.) can be burned at the site of work, which will result from atmospheric air pollution.

During the preparatory phase, surveys and typing of disturbed lands are carried out, the properties of cover soils are examined for 
suitability for biological reclamation; determine the directions and methods of reclamation; make feasibility studies and technical working projects on reclamation.

Preparatory work also includes the removal and storage of the upper fertile (humus) layer of soil together with forest floor in places where they are not disturbed (not swept away during the operation of the motor-pump). The preserved soil is further used in planting.

Restrictions on the use of forest land during preparatory work are conditioned by the need to comply with the procedure of felling in accordance with the provisions of the environmental legislation of Ukraine in the field of forestry.

The work directly from reclamation can be conditionally divided into three stages:

1. Geological exploration including pilot-industry extraction (PIE) with the extraction of discovered amber.

2. Mining technical reclamation.

3. Biological reclamation.

PIE and technical reclamation are carried out in a single set of works: the final stage of the PIE at each site is its technical reclamation, which includes planning, reclamation activities, waste disposal and more.

At certain stages of the work, a bulldozer is used to move the soil to the dump and to plan the surface. In some cases wheeled freight transport (dump truck) may be used.

Temporary dumps are arranged to accumulate cover and waste soil sand; for water reserve - sump.

All the heavy equipment that is planned to be used meets the current European requirements for ecology for off-road vehicles (emissions, noise, energy consumption, etc.).

During the technical phase, surface planning and filling of a layer of fertile soils are carried out. The purpose of phase - creating satisfactory conditions for the growth of trees and shrubs.

Disturbed lands are brought to a suitable state during technological works, or no later than one year after the end of the PIE.

The technical stage of reclamation after completion of the PIE will include the following set of works:

- selective formation of heaps;

- surface planning; 
- chemical reclamation;

- covering the planned surface with a layer of fertile soil or potentially fertile soil;

- engineering equipment of the territory (roads, exits).

After completion of the PIE stage and technical reclamation, special agro-ecological and agrochemical studies should be conducted to determine soil contamination, fertility (humus content), chemical and organic properties, etc. Based on the results of these studies, it will be necessary to prepare recommendations for a set of agro-chemical and agro-cultural activities and to establish a dendroplan of plantations.

Prior to the beginning of biological reclamation, the area of 2-3 years must be maintained or sown with annual crops to enrich the soil with nutrients (legumes, alfalfa, etc.). The fertility recovery method is chosen after the soil condition has been studied.

During the biological phase, measures are being taken to create highly productive, sustainable forest biogeocenoses, which are an important and beneficial factor for environmental impact.

Biological reclamation covers a complex of agro-technical and phytomeliorative measures to increase fertility of disturbed lands.

Forest reclamation involves the cultivation of a particular set of forest crops on the reclaimed lands.

Biological reclamation includes a set of measures to create waterair and nutrient regimes for forest species. Biological reclamation involves:

- introduction of sidereal rotations;

- introduction of high standards of organic and mineral fertilizers;

- mulching;

- deep loosening.

Reclamation measures on the topsoil should be maximally effective in order to reduce the recoupment of reclamation costs.

One of the most common areas of land reclamation is forest reclamation. Conducting of forest reclamation on disturbed lands allows to create forest plantations of various types and purpose, which helps to improve the natural environment, improve the sanitary and hygienic conditions of human life, while increasing the area of forest land. The process of natural restoration of ecosystems on disturbed lands begins with almost complete absence of living components. Formed empty ecological niches are first populated by microorganisms, fungi 
and algae, and then they are inhabited by higher plants, which passes spontaneously and without human participation. It should be noted that this natural process of ecosystem formation is very long, so there is a need for artificial restoration of vegetation.

Staged forest reclamation is usually carried out in most countries, and direct reclamation is performed only on the richest soils. In the step-by-step forest reclamation, soil-improving plants are first planted and then replaced with more valuable forest tree species. Reforestation activities depend on many interrelated factors.

Factors that determine and influence the choice of forest restoration measures in disturbed areas:

- physical, geographical and climatic features of the area; soils;

- physicochemical properties of the soil cover and underlying

- area of the violated territory;

- forestry use of the territory until the moment of disturbance;

- promising targeted use of the restored territory.

- the amount of capital expenditures on timber and reclamation measures;

- availability of material and technical resources;

- social effect of phytomeliorative and reclamation works.

Restoration of forest vegetation on disturbed lands depends on the suitability of soils to create vegetation, which directly affects the technological process itself. Restoration of forest vegetation on disturbed lands depends to a large extent on the suitability of soils and potentially fertile species to cover vegetation. The soil mixture formed after the illegal extraction of amber will differ markedly from the previous composition of soils in its physicochemical composition. In this case, an important factor is conducting appropriate research. In this case, the main criteria for fertility should include: granulometric composition, water-physical features, indicators of salinity and acidity, humus and nutrition. It is also important to provide for the conditions of each ecotope a set of suitable species of tree species, since reproduction of the forest environment as close as possible to the original is the main purpose of the work.

As noted above, reclamation involves the preparation, technical and biological stages of the work. 
The most important, biological, stage is the creation of artificial forest plantations of different purpose (protective, reclamation, landscaping, plantation, etc.) and is performed by forestry enterprises after mining technical reclamation. it includes measures to restore the fertility of disturbed lands for the cultivation of agricultural and forest crops. It is necessary to start the biological stage as soon as possible, in order to prevent the compacting of loose or level soils, the deterioration of their properties and the spread of weeds and manifestations of water and wind erosion.

The biological reclamation of disturbed lands depends on the composition and properties of the rocks and soils, the physical and geographical conditions of the environment, and the nature of the further use of the reclaimed lands. Soils are classified by suitability for biological reclamation into: suitable, unsuitable and unsuitable.

In biological reclamation widely used herbaceous plants. They quickly anchor the soil mixture and help stop wind and water erosion. In addition, herbaceous plants activate the soil-forming process on the dumps. The species composition of plants used in the creation of vegetation cover in disturbed lands is determined by the natural climatic factors and the water-physical properties of the soil mixture. Common properties for most soil mixtures of disturbed lands - unstructured, poor hydrological regime and nutrient poverty.

Biological reclamation as a set of measures to create a favourable water and air and soil nutrient regimes of forest plantations for different purpose, forestry companies performed after mine reclamation. This set of measures is determined by the physical and chemical properties of the underlying soils and involves the introduction of crop rotations, saturated with crops for sideral fertilizer, introduction of high standards of organic and mineral fertilizers, mulching, etc. It is necessary to start the biological stage as soon as possible in order to prevent compaction of uneven soil soils, deterioration of their properties, as well as the spread of weeds and adventitious species of herbaceous plants and manifestations of water and wind erosion.

It should be noted that the main mechanism of transformation of soil mixture into lithosomes (embryosomes) is the mineralization and transformation of organic matter by microbiological processes. The process of development of lithosomes (embryosomes) includes the following stages: humus accumulation or peat accumulation, leaching 
of carbonates and removal of soluble salts, structural reorganization of the solid phase, weathered primary materials and glaze. This process is slow.

It should also be noted that forest biogeocenoses are of great importance for solving the problem of restoration, stabilization and protection of the environment. Therefore the choice of direction reclamation should be consistent with the functional features of the landscape.

Experience of reclamation of disturbed lands of Rivne region involves application, after returning of fertile layer of soil to the surface, sowing of perennial lupine and rye.

Since during the illegal extraction of amber, the fertile soil layer was not preserved at all but only destroyed, it is not possible to return it to the level surface of the plots. That is, the environment for the creation of primary vegetation is generally unfavourable.

Therefore, it is considered advisable to apply organic fertilizers after levelling and sealing the surface of the sections, namely peat to increase fertility and to prevent compaction of uneven soil and to form a hard crust. Peat is spread evenly over the entire area of the plots. It should be evenly distributed over the level surface of the plots, in the volume of $30-60 \mathrm{t} / \mathrm{ha}$.

The next step is to grow perennials and white lupines to increase fertility and protect pine seedlings from weeds, adventitious herbs and fires.

In the future, the creation of forest crops on disturbed lands greatly intensifies and accelerates the process of soil formation, where not least the breed composition of plantations plays. When selecting wood and shrub species for planting on disturbed lands, the most suitable are native species adapted to the conditions of this region.

After afforestation, the land is transferred to the user for continued use as intended.

Another option, which can be considered as an alternative, is to transfer forest land to another category of land.

An example is the creation of a forest lake with the restoration of part of the forest area. Such a reservoir can have both recreational and technological purpose - as a reservoir for fire or other purposes. The advantage of this option is its lower cost compared to the option of complete restoration of vegetation. 
An alternative to the recalmation technology may be the exclusion of the PIE phase of the site. However, refusal to remove the amber remnants makes efforts to restore the natural environment of the affected areas useless, since it does not guarantee the return of the diggers, there are several difficulties of technical (mechanical) reclamation.

An illegal extraction of amber was carried out mainly by hand by chance tool, as well as a hydromechanized method to a depth of $6 . .8 \mathrm{~m}$, which led to the formation of large areas disturbed by holes, mounds and emissions of sand mass up to $1 \mathrm{~m}$ and continuous filling of the surface of the soil. The chaotic location of the holes and the extraction holes makes it impossible to carry out the maintenance and ordering of the forest. Mechanical interference with the soil horizons and soil hydrosurface also led to disruption of the natural system of sediment infiltration, the formation of numerous local zones of saturation with moisture, while simultaneously sealing their periphery, which changed the natural physical and mechanical properties of the soil horizons.

As a result of earthworks from the illegal extraction of amber, the soils have had a very significant impact: mixing of layers, watering the exits of groundwater and atmospheric precipitation, opening the lower horizons (humus-eluvial, eluvial, and even illuvial), precipitation and transformation of their physical and chemical properties under the influence of wind, temperatures and humidity. As a consequence, the light mineral substrate is significantly compacted and cemented, the fertile layer is lost and cannot be recovered naturally.

The chaotic nature of the disturbance of the soil layer makes it impossible to conduct a separate remediation of degraded areas. Permanent reclamation of the territories of all disturbed species is necessary with the preliminary removal of all vegetation cover and carrying out planning works at the stage of technical reclamation.

The above factors significantly hinder, first of all, the technical stage of reclamation. Mechanical backfilling holes and planning surface after removing residual stand will create zones of varying density, leading to the formation of numerous local depression. In order to equalize depression after a year, it will be necessary to re-plan the surface. According to the existing methodological recommendations, after the stage of technical reclamation it is necessary to maintain a 
certain period during which the soil masses stabilize; such period should last up to at least 3-5 years (after PIE - 2-3 years).

The effectiveness of possible alternative technical solutions, such as mechanical soil compaction by loading and / or periodic wetting, is doubtful not only in view of the high resource and energy costs, but also because they do not provide the necessary uniformity of the mineral soil substrate.

\section{Conclusions}

Thus, as a result of studies found that the issue of reclamation, due to the illegal extraction of amber, to prevent a possible environmental disaster of amber containing areas of Rivne, Volyn and Zhytomyr regions of Ukraine are sharp enough and needs urgent solutions, especially at the legislative level.

It is established that plant communities, which spontaneously and slowly develop in disturbed areas, differ from the original phytocenoses. In addition, the drainage ditches significantly violated the hydrological regime, there is a drying up of the territory, which causes the weakening of stands, loss of environmental sustainability and negative vegetation dynamics.

Considering this, it is necessary to carry out continuous reclamation of the sites, which were damaged as a result of illegal extraction of amber.

Studies have found that it is advisable to carry out the rehabilitation of disturbed lands in conjunction with pilot-industrial extraction for the complete removal of amber in order to protect the reclaimed land from unauthorized actions in the future.

Thus, the removal of forest residues and the complete development of land in an open manner is a necessary stage of reclamation. After completion of the pilot-industrial extraction and technical reclamation, additional ecological and economic evaluation of the affected areas should be carried out in order to further extract amber, afforestation and use for agricultural production.

\section{References}

1. Malanchuk E.Z., Kornienko V.Ya., Volk P.P., Vasylchuk O.Yu., Semenyuk V.V. Reclamation of disturbed lands as a result of illegal amber production. Current scientific research in the modern world. Journal. Pereyaslav-Khmelnitsky,. 5 (37), pp. 1 - 170, p.87-90, (2018) 
2. Kornienko V. Modern technologies of amber extraction from fields. Bulletin of NUSPD. Engineering Sciences: Coll. of sciences. wash. 1 (65), Rivne, p. 449-457, (2014)

3. Industrial amber mining technologies. Monograph. Bulat A.F., Nadutyi V.P., Malanchuk E.Z., Malanchuk Z.R., Kornienko V.Ya. Monograph: Dnipro, Exactly: IGTM-NUVPP, p. 237, (2017)

4. Special technologies of mining. Malanchuk Z.R., Malanchuk E.Z., Kornienko V.Ya. Tutorial. Exactly: NSULP, p. 290, (2017)

5. Modern geotechnical methods of management of the process of amber extraction. Malanchuk E.Z., Malanchuk Z.R., Korniyenko V.Ya. Monograph: «Innovative development of resource-saving technologies of mining of minerals» «St. Ivan Rilsky» Mining and Mining University of Geology (Sofia, Bulgaria), 439p, 80-103 pp., (2018)

6. Physical-mechanical and technological features of amber extraction in the Rivne-Volyn region of Ukraine. Malanchuk Z.R., Soroka V.S., Lahodniuk O.A., Marchuk M.M. Topical scientific researches into resource-saving technologies of mineral mining and processing. Multi-authored monograph. - Sofia: Publishing House «St.Ivan Rilski», 6-24 pp., 446 p. (2020)

7. Malanchuk, Z., Korniienko, V., Malanchuk, Y., Moshynskyi, V. Analyzing vibration effect on amber buoying up velocity. E3S Web of Conferences 123, 01018 (2019). Ukrainian School of Mining Engineering. DOI: 10.1051/e3sconf/201912301018

8. Malanchuk, Y., Korniienko, V., Moshynskyi, V., Soroka V., Khrystyuk, A., Malanchuk, Z. Regularities of hydromechanical amber extraction from sandy deposits. Mining of mineral deposits. (2019). DOI: 10.33271/mining13.01.049

9. Z. Malanchuk, V. Moshynskyi, Y. Malanchuk, V. Korniienko. PhysicoMechanical and Chemical Characteristics of Amber. Non-Traditional Technologies in the Mining Industry. Trans Tech Publications Inc. Solid State Phenomena (277), pp. 80-89, (2018). doi: https://doi.org/10.4028/www.scientific.net/SSP.277

10. Malanchuk Z., Malanchuk Y., Khrystiuk A. Mathematical Modeling Of Hydraulic Mining From Placer Deposits Of Minerals. Mining Of Mineral Deposits. V 10 (2). pp.: 18-24. (2016). DOI: 10.15407/mining10.02.013

11. Malanchuk Z., Korniienko V., Malanchuk E., Khrystiuk A. Results of experimental studies of amber extraction by hydromechanical method in Ukraine. Eastern - European Journal of Enterprise Technologies / PC «Technology Center», Kharkiv, Ukraine, Volume 3/10(81), pp. 24-28. (2016). ISSN 1729-3774, UDC 622.232.5:622.2 DOI: 10.15587/1729-4061.2016.72404

12. Nadutyi, V., Korniyenko, V., Malanchuk, Z., Cholyshkina, O. Analytical presentation of the separation of dense suspensions for the extraction of amber. E3S Web of Conferences 109, 00059 (2019). Essays of Mining Science and Practice. DOI: 10.1051/e3sconf/20191090005 